\title{
Nickel oxalate dihydrate nanorods attached to reduced graphene oxide sheets as a high-capacity anode for rechargeable lithium batteries
}

\author{
Hyo-Jin $\mathrm{Oh}^{1,6}$, Chang-Heum Jo, ${ }^{1,6}$, Chong Seung Yoon ${ }^{2}$, Hitoshi Yashiro ${ }^{3}$, Sun-Jae Kim ${ }^{1}$, Stefano Passerini ${ }^{4}$, \\ Yang-Kook Sun ${ }^{5}$ and Seung-Taek Myung ${ }^{1}$
}

In the search for high-capacity anode materials, a facile hydrothermal route has been developed to synthesize phase-pure $\mathrm{NiC}_{2} \mathrm{O}_{4} \cdot 2 \mathrm{H}_{2} \mathrm{O}$ nanorods, which were crystallized into the orthorhombic structure without using templates. To ensure the electrical conductivity of the nanorods, the produced $\mathrm{NiC}_{2} \mathrm{O}_{4} \cdot 2 \mathrm{H}_{2} \mathrm{O}$ nanorods were attached to reduced graphene oxide ( $\mathrm{rGO}$ ) sheets via self-assembly layer-by-layer processes that utilize the electrostatic adsorption that occurs in a poly(diallyldimethylammonium chloride) solution. The high electrical conductivity aided by the presence of rGO significantly improved the electrochemical properties: $933 \mathrm{mAh} \mathrm{g}^{-1}$ for the charge capacity (oxidation), which showed $87.5 \%$ efficiency at the first cycle with a retention of approximately $85 \%$ for 100 cycles, and $586 \mathrm{mAh} \mathrm{g}^{-1}$ at $10 \mathrm{C}$-rates $\left(10 \mathrm{Ag}^{-1}\right)$ for the $\mathrm{NiC}_{2} \mathrm{O}_{4} \cdot 2 \mathrm{H}_{2} \mathrm{O} / \mathrm{rGO}$ electrode. The lithium storage processes were involved in the conversion reaction, which were fairly reversible via a transformation to Ni metal accompanied by the formation of a lithium oxalate compound upon discharge (reduction) and restoration to the original $\mathrm{NiC}_{2} \mathrm{O}_{4} \cdot 2 \mathrm{H}_{2} \mathrm{O}$ upon charging (oxidation); this was confirmed via X-ray diffraction, transmission electron microscopy, X-ray photoelectron microscopy and time-of-flight secondary ion mass spectroscopy. We believe that the high rate capacity and rechargeability upon cycling are the result of the unique features of the highly crystalline $\mathrm{NiC}_{2} \mathrm{O}_{4} \cdot 2 \mathrm{H}_{2} \mathrm{O}$ nanorods assisted by conducting rGOs.

NPG Asia Materials (2016) 8, e270; doi:10.1038/am.2016.59; published online 20 May 2016

\section{INTRODUCTION}

The demand for sustainable and green-energy sources is rising because of increasing concerns regarding fast population growth and industrialization worldwide. Lithium-ion batteries have been developed as power sources over several decades and have achieved great commercial success, ranging from mobile to stationary applications. ${ }^{1-4}$ Rechargeable lithium-ion batteries are suitable for the aforementioned applications because of their high energy density and high power properties. ${ }^{5,6}$ In commercial batteries, graphite is commonly adopted as the active material for the negative electrodes. Apart from its ability to accommodate $\mathrm{Li}^{+}$ions in its structure and its reversibility, the theoretical capacity of graphite is limited to $372 \mathrm{mAh} \mathrm{g}^{-1}$. The predominant intercalation potential of graphite is approximately $0.1 \mathrm{~V}$ vs $\mathrm{Li} / \mathrm{Li}^{+}$, which results in risks associated with short circuits derived from dendritic growth of Li. In the past, efforts have been made to find high-capacity alternative electrode materials to replace graphite. These new materials can be classified based on their reaction mechanisms: (i) intercalation: Ti-based oxides that store
$\mathrm{Li}^{+}$ions in the host structure, such as $\mathrm{TiO}_{2}{ }^{8,9}$ and $\mathrm{Li}_{4} \mathrm{Ti}_{5} \mathrm{O}_{12},{ }^{10,11}$ (ii) alloy: $\mathrm{Si}$ - and Sn-based materials that undergo reactions through de-alloy/alloy processes with $\mathrm{Li}^{12,13}$ and (iii) conversion: metal oxides, fluorides or sulfides that are converted to metal and Li-A (A: O, F and S). ${ }^{14-17}$ Repetitive $\mathrm{Li}^{+}$insertion/extraction in Ti-based oxides is known to retain its capacity upon cycling, even though the capacity is small. Although Si and Sn are known to deliver high capacity, these materials experience serious volume expansion, $>300 \%$ for $\mathrm{Li}_{4.4} \mathrm{Si} 18$ and $>359 \%$ for $\mathrm{Li}_{4.4} \mathrm{Sn},{ }^{19}$ when fully discharged (reduced), which results in poor electrode performance. For the conversion process, a phase transformation during the first discharge results in structural amorphization of the transition metals, after which the metals are restored to their original state charge, even though the reaction proceeded in an amorphous state. $^{20-23}$ Apart from their high capacities, however, poor kinetics and the large difference between the operation voltages for charge and discharge should be improved to compete with intercalation compounds.

\footnotetext{
${ }^{1}$ Department of Nano Engineering, Sejong University, Seoul, South Korea; ${ }^{2}$ Department of Material Science and Engineering, Hanyang University, Seoul, South Korea; ${ }^{3}$ Department of Chemical Engineering, Iwate University, Iwate, Japan; ${ }^{4}$ Electrochemistry I, Helmholtz Institute UIm (HIU), UIm, Germany and ${ }^{5}$ Department of Energy Engineering, Hanyang University, Seoul, South Korea

${ }^{6}$ These authors contributed equally to this work.

Correspondence: Professor Y-K Sun, Department of Energy Engineering, Hanyang University, Seoul 133-791, South Korea.

E-mail: yksun@hanyang.ac.kr

or Professor S-T Myung, Department of Nano Engineering, Sejong University, Seoul 143-747, South Korea.

E-mail: smyung@sejong.ac.kr

Received 4 November 2015; revised 19 February 2016; accepted 22 February 2016
} 
Indeed, the use of a high-capacity anode is required to increase the resulting cell capacity. Although the capacity of graphite is limited, its electrochemical properties are still superior to other electrode materials in terms of capacity retention and rate capability. Recently, new conversion-type materials were introduced by Tirado's group ${ }^{24-27}$ ; these materials showed intriguing electrochemical performance using metal oxalates $\mathrm{MC}_{2} \mathrm{O}_{4}$ (M: $\mathrm{Mn}, \mathrm{Fe}, \mathrm{Co}, \mathrm{Ni}, \mathrm{Cu}, \mathrm{Zn}$ ), delivering $700-900 \mathrm{mAh} \mathrm{g}^{-1}$ in several early cycles. Among these metal oxalates, $\mathrm{NiC}_{2} \mathrm{O}_{4}$ delivered the highest capacity. However, their capacities gradually faded with further cycling. ${ }^{24}$ Tirado's group also suggested a possible mechanism during the first lithiation: $\mathrm{MC}_{2} \mathrm{O}_{4}+2 \mathrm{Li}^{+}+2 \mathrm{e}^{-}$ $\rightarrow \mathrm{M}+\mathrm{Li}_{2} \mathrm{C}_{2} \mathrm{O}_{4} \cdot{ }^{25-27}$ By contrast, it is not clear whether the presence of oxalate ions can be solely ascribed to the formation of $\mathrm{Li}_{2} \mathrm{C}_{2} \mathrm{O}_{4}$ because the oxalate ions were present in both unreacted $\mathrm{MC}_{2} \mathrm{O}_{4}(\mathrm{M}: \mathrm{Co})$ and $\mathrm{Li}_{2} \mathrm{C}_{2} \mathrm{O}_{4} \cdot{ }^{25}$ Interestingly, thermal decomposition of metal oxalates as precursors usually leads to the production of metal oxides. However, metal oxalates seem to show better lithium storage abilities than metal oxides, although the reason is not clear. ${ }^{24-29}$ Enhancement of electrical conductivity is another important concern for electrode materials. Coating using carbonaceous substances has been widely accepted as an effective strategy to achieve better conduction properties and to thereby improve electrochemical properties, such as cycling performance and rate capability. Modification with reduced graphene oxide (rGO) results in better contact with electrolytes, and its conducting property improves the resulting electrical conductivity assisted by the electro-conducting rGO; this leads to the improved mobility of $\mathrm{Li}^{+}$ions in the channels between the active particles supported by rGO.

Metal oxalates can be produced via solid-state reactions, ${ }^{30}$ spray pyrolysis, ${ }^{31}$ reverse-micellar route methods, ${ }^{32}$ solvothermal reactions, ${ }^{33}$ sol-gel methods, ${ }^{34,35}$ hydrothermal methods ${ }^{36}$ and microwave-assisted solution approaches. ${ }^{37}$ In this work, we successfully synthesized $\mathrm{NiC}_{2} \mathrm{O}_{4} \cdot 2 \mathrm{H}_{2} \mathrm{O}$ nanorods via a facile hydrothermal method. These unique one-dimensional nanorods give rise to two important features: (i) shortened pathways for the $\mathrm{Li}^{+}$ions and electrons provided by the two-dimensional nanostructure of rGO and (ii) sufficient voids for electrolyte penetration into the electrodes resulting in volumetric availability when lithiated. The produced $\mathrm{NiC}_{2} \mathrm{O}_{4} \cdot 2 \mathrm{H}_{2} \mathrm{O}$ nanorods were also sandwiched between rGO plates followed by layer-by-layer self-assembly (Figure 1a), which enabled a significant improvement in the electrical conductivity of the $\mathrm{NiC}_{2} \mathrm{O}_{4} \cdot 2 \mathrm{H}_{2} \mathrm{O} / \mathrm{rGO}$ composite. To the best of our knowledge, this is the first report that presents $\mathrm{NiC}_{2} \mathrm{O}_{4} \cdot 2 \mathrm{H}_{2} \mathrm{O}$ and $\mathrm{NiC}_{2} \mathrm{O}_{4} \cdot 2 \mathrm{H}_{2} \mathrm{O} / \mathrm{rGO}$ as possible anode materials for rechargeable lithium batteries.
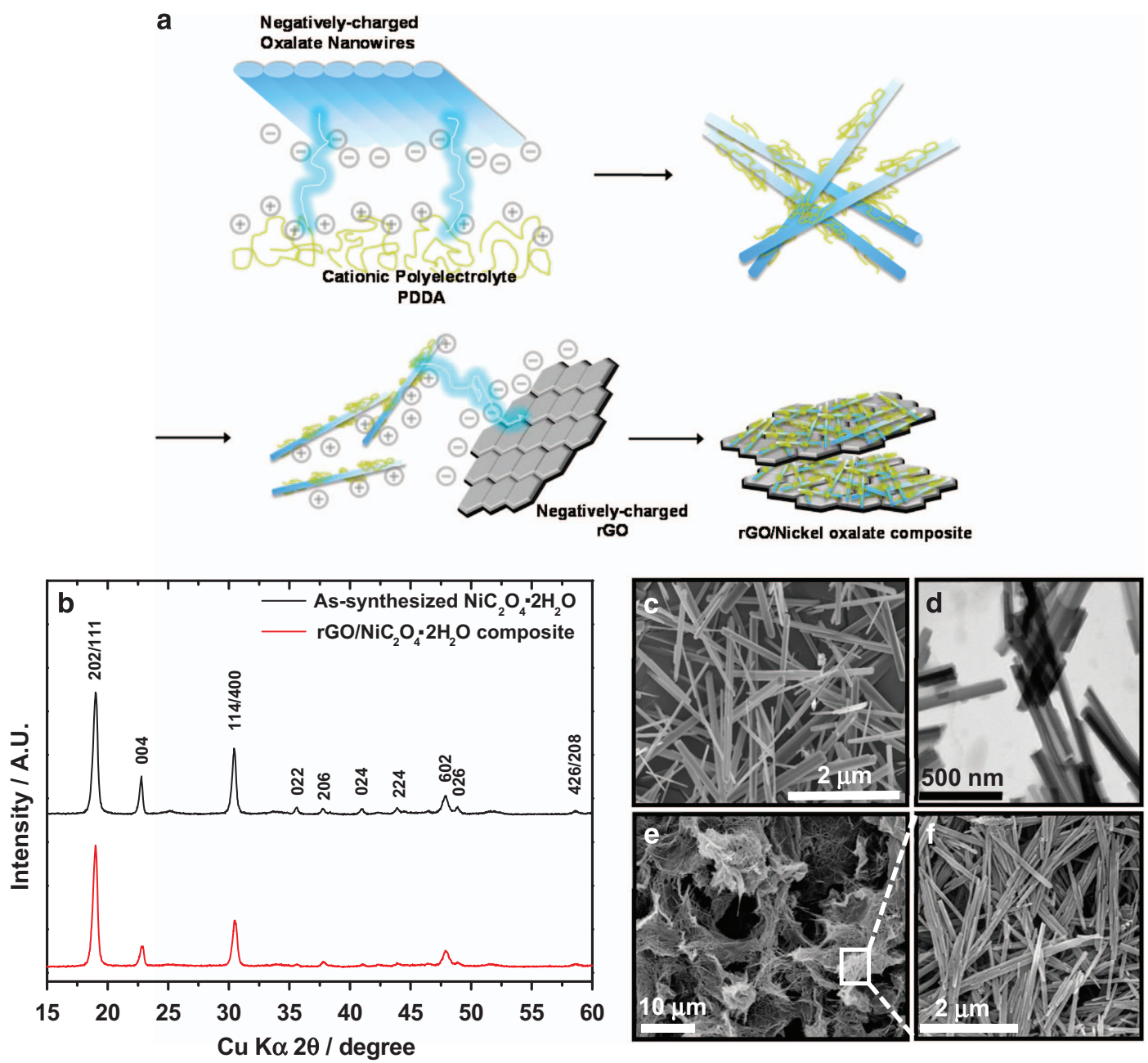

Figure 1 (a) Schematic of the formation process for the $\mathrm{NiC}_{2} \mathrm{O}_{4} \cdot 2 \mathrm{H}_{2} \mathrm{O} / \mathrm{rGO}$ composite; (b) XRD patterns of the as-synthesized $\mathrm{NiC}_{2} \mathrm{O}_{4} \cdot 2 \mathrm{H}_{2} \mathrm{O}$ (top) and the $\mathrm{NiC}_{2} \mathrm{O}_{4} \cdot 2 \mathrm{H}_{2} \mathrm{O} / \mathrm{rGO}$ composite (bottom); (c) SEM and (d) TEM bright-field images of the as-synthesized $\mathrm{NiC}_{2} \mathrm{O}_{4} \cdot 2 \mathrm{H}_{2} \mathrm{O}$ nanorods; (e) SEM images of the as-synthesized $\mathrm{NiC}_{2} \mathrm{O}_{4} \cdot 2 \mathrm{H}_{2} \mathrm{O} / \mathrm{rGO}$ composite; and (f) a magnified image from panel (e) that highlights the morphology of the $\mathrm{NiC}_{2} \mathrm{O}_{4} \cdot 2 \mathrm{H}_{2} \mathrm{O}$ nanorods attached onto the rGO sheets. 
Another novelty is the success in anchoring $\mathrm{NiC}_{2} \mathrm{O}_{4} \cdot 2 \mathrm{H}_{2} \mathrm{O}$ nanorods onto rGO sheets via a self-assembly layer-by-layer (SA-LBL) process that utilizes electrostatic adsorption. This finding is very significant because the composite electrodes exhibited remarkable electrode performance, including high capacity, retention and rate capability. Furthermore, we studied the related reaction for a better understanding of the suggested conversion reaction for metal oxalates, which are suitable for use in lithium storage. This report introduces the aforementioned novelties and the reaction mechanism of $\mathrm{NiC}_{2} \mathrm{O}_{4} \cdot 2 \mathrm{H}_{2} \mathrm{O} / \mathrm{rGO}$ composite when reacting with $\mathrm{Li}^{+}$ions for rechargeable lithium batteries.

\section{EXPERIMENTAL PROCEDURES}

\section{Synthesis of $\mathrm{NiC}_{2} \mathrm{O}_{4} \cdot 2 \mathrm{H}_{2} \mathrm{O}$}

All reagents used in the experiments were of analytical grade (Junsei, Tokyo, Japan) and used without further purification. Distilled water was used for all synthesis and treatment processes. $\mathrm{NiCl}_{2} \cdot 6 \mathrm{H}_{2} \mathrm{O}(0.001 \mathrm{M}), \mathrm{Na}_{2} \mathrm{C}_{2} \mathrm{O}_{4}(0.005 \mathrm{M})$, distilled water $(9 \mathrm{ml})$ and ethylene glycol $(\mathrm{EG}, 16 \mathrm{ml})$ were first mixed in a beaker, and the mixed solution was stirred at room temperature for $6 \mathrm{~h}$ to form a clear solution. The solution was then transferred into a Teflon-lined stainless steel autoclave (100 $\mathrm{ml}$ capacity). The autoclave was hermetically sealed and heated at $130-200^{\circ} \mathrm{C}$ for $12 \mathrm{~h}$. After the reaction, the autoclave was cooled to room temperature. Finally, the products were washed three times with de-ionized water and ethanol and then dried at $80^{\circ} \mathrm{C}$ for $24 \mathrm{~h}$ in a vacuum oven.

\section{Synthesis of the SA-LBL $\mathrm{NiC}_{2} \mathrm{O}_{4} \cdot 2 \mathrm{H}_{2} \mathrm{O} / \mathrm{rGO}$ composite}

The as-synthesized $\mathrm{NiC}_{2} \mathrm{O}_{4} \cdot 2 \mathrm{H}_{2} \mathrm{O}$ powders $(1.5 \mathrm{~g})$ were sonicated in distilled water $(100 \mathrm{ml})$ for $10 \mathrm{~min}$ to produce a homogeneous $\mathrm{NiC}_{2} \mathrm{O}_{4} \cdot 2 \mathrm{H}_{2} \mathrm{O}$ suspension, and poly(diallyldimethylammonium chloride) (PDDA, $15 \mathrm{ml}$ ) was subsequently added to the suspension, which was vigorously stirred for $30 \mathrm{~min}$. Then the suspension was mixed with rGO $(50 \mathrm{mg}$, IDT International, Ulsan, Korea) and stirred for $1 \mathrm{~h}$. During this process, the color of the solution changed from sky blue to black. The product was isolated and the residual PDDA was removed through centrifugation rotated at 10000 r.p.m. for $30 \mathrm{~min}$, followed by two cycles of consecutive washing/centrifugation with water. Finally, the products were dispersed in water to produce a colloidal $\mathrm{NiC}_{2} \mathrm{O}_{4} \cdot 2 \mathrm{H}_{2} \mathrm{O} / \mathrm{PDDA} / \mathrm{rGO}$ suspension, after which the suspension was dried in a vacuum at $80^{\circ} \mathrm{C}$ overnight.

\section{Physical properties}

The crystalline phases of the products were characterized by powder X-ray diffraction (XRD, Rint-2000, Rigaku, Tokyo, Japan) using $\mathrm{Cu}-\mathrm{K} \alpha$ radiation. The XRD data were obtained with a step size of $0.03^{\circ}$ and a count time of $1 \mathrm{~s}$. The particle morphologies of the produced powders were analyzed using scanning electron microscopy (JXA-8100, JEOL, Tokyo, Japan) and transmission electron microscopy (TEM; H-800, Hitachi, Tokyo, Japan). The DC electric conductivity was measured by a direct volt-ampere method (CMTSR1000, AIT, Gyeonggi, Korea), in which disc samples were contacted by a four-point probe. An elemental analyzer (EA110, CE Instrument, Manchester, UK) was employed to determine the amount of carbon in the final products. A time-of-flight secondary ion mass spectroscopy (ToF-SIMS, PHI TRIFT V nanoTOF, ULVAC-PHI, Kanagawa, Japan) surface analyzer, equipped with a liquid $\mathrm{Bi}^{+}$ion source and pulse electron flooding, was operated at $10^{-9}$ Torr. During the analysis, the targets were bombarded by $10 \mathrm{keV} \mathrm{Bi}^{+}$beams with a pulsed primary ion current varying from 0.3 to $0.5 \mathrm{pA}$. The total collection time was 100 s over a $200 \times 200 \mu \mathrm{m}^{2}$ area. X-ray photoelectron spectroscopic (XPS, PHI5600, Perkin-Elmer, Boston, MA, USA) measurements were performed to obtain information on the surface states of electrodes in a macro-mode $\left(3 \times 3 \mathrm{~mm}^{2}\right)$. The samples were first transferred into a hermitically sealed transfer chamber in the glove box, and they were again transferred into the vacuum chamber of XPS machine, thus no exposure to air and water molecules for XPS measurement.

\section{Electrochemical properties}

The electrochemical properties were measured in R2032 coin-type cells. The electrodes were fabricated from a mixture of the prepared metal oxalate powders (85 wt.\%), ketjen black (5 wt.\%), super-P (5 wt.\%) and polyacrylic acid (5 wt.\%) in $\mathrm{N}$-methylpyrrolidinone. The obtained slurry was applied onto copper foil and dried in an oven at $80{ }^{\circ} \mathrm{C}$ for $1 \mathrm{~h}$. The electrode was further dried overnight at $80^{\circ} \mathrm{C}$ under a vacuum. The electrolyte solution used was $1 \mathrm{M}$ $\mathrm{LiPF}_{6}$ in a 3:7 volume mixture of ethylene carbonate and dimethyl carbonate. The fabricated cells were charged and discharged in a range of $0-3 \mathrm{~V}$ applied at a constant current of $500 \mathrm{mAg}^{-1}$ at $25^{\circ} \mathrm{C}$.

\section{RESULTS AND DISCUSSION}

\section{Synthesis of the SA-LBL $\mathrm{NiC}_{2} \mathrm{O}_{4} \cdot 2 \mathrm{H}_{2} \mathrm{O} / \mathrm{rGO}$ composite}

Hydrothermal reactions under various conditions resulted in phasepure products crystallized into an orthorhombic structure with the $\mathrm{Cccm}$ space group (Figure $1 \mathrm{~b}$ of the XRD pattern, Figures $1 \mathrm{c}$ and $\mathrm{d}$ of the scanning electron microscopic and TEM images, Supplementary Figure S1), although the resulting crystallinity varied depending on the reaction conditions. When reacted at $130{ }^{\circ} \mathrm{C}$, the resulting products were urchin-like nanorods. At $170{ }^{\circ} \mathrm{C}$, the urchin-like $\mathrm{NiC}_{2} \mathrm{O}_{4} \cdot 2 \mathrm{H}_{2} \mathrm{O}$ nanorod assembly was separated into individual nanorods owing to the growth of the nanorods in thickness and length, indicating that the length of $\mathrm{NiC}_{2} \mathrm{O}_{4} \cdot 2 \mathrm{H}_{2} \mathrm{O}$ nanorods increased with the increasing reaction temperature (Supplementary Figure $\mathrm{S} 1$ ). For this reason, we decided that the best conditions were $170{ }^{\circ} \mathrm{C}$ for $12 \mathrm{~h}$ for the morphology that exhibited the most appropriate dispersion.

We also attempted to apply the SA-LBL process on planar rGO substrates, as shown schematically in Figure 1a. First, negatively charged $\mathrm{NiC}_{2} \mathrm{O}_{4} \cdot 2 \mathrm{H}_{2} \mathrm{O}$ was mixed with positively charged PDDA to form $\mathrm{PDDA}$-wrapped $\mathrm{NiC}_{2} \mathrm{O}_{4} \cdot 2 \mathrm{H}_{2} \mathrm{O} \quad\left(\mathrm{NiC}_{2} \mathrm{O}_{4} \cdot 2 \mathrm{H}_{2} \mathrm{O} / \mathrm{PDDA}\right)$ via electrostatic interactions. Second, the positively charged PDDA/ $\mathrm{NiC}_{2} \mathrm{O}_{4} \cdot 2 \mathrm{H}_{2} \mathrm{O}$ was then dipped into an rGO dispersion, after which the negatively charged graphene sheets self-assembled on the surface of $\mathrm{NiC}_{2} \mathrm{O}_{4} \cdot 2 \mathrm{H}_{2} \mathrm{O} / \mathrm{PDDA}$ to yield $\mathrm{NiC}_{2} \mathrm{O}_{4} \cdot 2 \mathrm{H}_{2} \mathrm{O} / \mathrm{PDDA} / \mathrm{rGO}$. After drying in a vacuum, the PDDA was evaporated, thereby producing the $\mathrm{NiC}_{2} \mathrm{O}_{4} \cdot 2 \mathrm{H}_{2} \mathrm{O} / \mathrm{rGO}$ composite. The resulting XRD data (Figure $1 \mathrm{~b}$, bottom) coincided with that of $\mathrm{NiC}_{2} \mathrm{O}_{4} \cdot 2 \mathrm{H}_{2} \mathrm{O}$ (Figure 1b, top), indicating that the SA-LBL process did not alter the original crystal structure. The rGO-related peaks were not found in the XRD pattern, which is a result of the low crystallinity of the rGO. Recently, Feng et al. ${ }^{38}$ reported the synthesis of $\mathrm{Cu}_{1 / 3} \mathrm{Co}_{2 / 3} \mathrm{C}_{2} \mathrm{O}_{4} \cdot \mathrm{xH}_{2} \mathrm{O} /$ functionalized graphene oxide via an additional hydrothermal treatment of $\mathrm{Cu}_{1 / 3} \mathrm{Co}_{2 / 3} \mathrm{C}_{2} \mathrm{O}_{4} \cdot \mathrm{xH}_{2} \mathrm{O}$ and functionalized graphene oxide (FGO) in which the $\mathrm{Cu}_{1 / 3} \mathrm{Co}_{2 / 3} \mathrm{C}_{2} \mathrm{O}_{4} \cdot \mathrm{xH}_{2} \mathrm{O} / \mathrm{FGO}$ composite exhibited several unindexable impurities with the formation of nanosized nanoparticles with $\mathrm{Cu}_{1 / 3} \mathrm{Co}_{2 / 3} \mathrm{C}_{2} \mathrm{O} 4 \cdot \mathrm{xH}_{2} \mathrm{O}$ nanorods. These nanorods could be identified as a mixture of two crystal systems, monoclinic $(C 2 / c)$ and orthorhombic (Pnnm), according to their XRD patterns. Their products included metal-like nanoparticles ranging from 5 to $10 \mathrm{~nm}$ in diameter, indicating that the second hydrothermal reaction with their homemade FGO resulted in structural and morphological changes. The similarity in the crystal structure that showed the two crystal systems was also observed in $\mathrm{FeC}_{2} \mathrm{O}_{4} \cdot 2 \mathrm{H}_{2} \mathrm{O},{ }^{39}$ which was synthesized at room temperature and consecutive drying at $60^{\circ} \mathrm{C}$. This highlights the advantage of the present SA-LBL process because the reaction was carried out at room temperature. Thus the synthesis conditions did not damage or affect the crystal structure or morphology of the $\mathrm{NiC}_{2} \mathrm{O}_{4} \cdot 2 \mathrm{H}_{2} \mathrm{O}$, which maintained the original orthorhombic structure with the $\mathrm{Cccm}$ space group. Removing crystal water from both $\mathrm{NiC}_{2} \mathrm{O}_{4} \cdot 2 \mathrm{H}_{2} \mathrm{O}$ and $\mathrm{NiC}_{2} \mathrm{O}_{4} \cdot 2 \mathrm{H}_{2} \mathrm{O} / \mathrm{rGO}$ at $180^{\circ} \mathrm{C}$ for $5 \mathrm{~h}$ in air resulted in the formation of $\mathrm{NiC}_{2} \mathrm{O}_{4}$ (Supplementary Figure S2a, top), which 
a
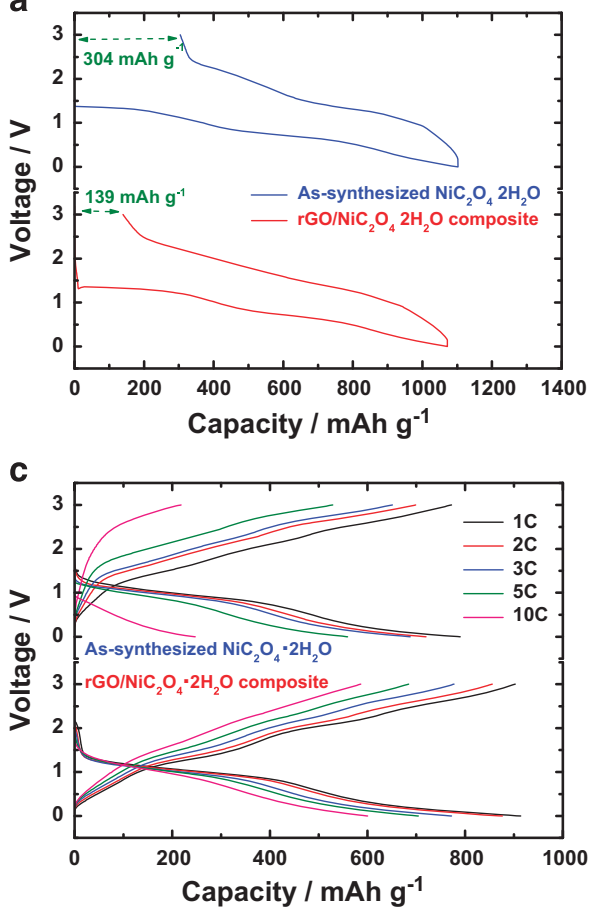

b

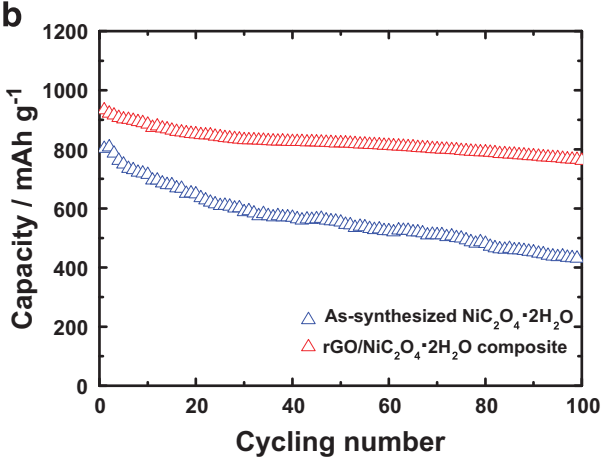

d

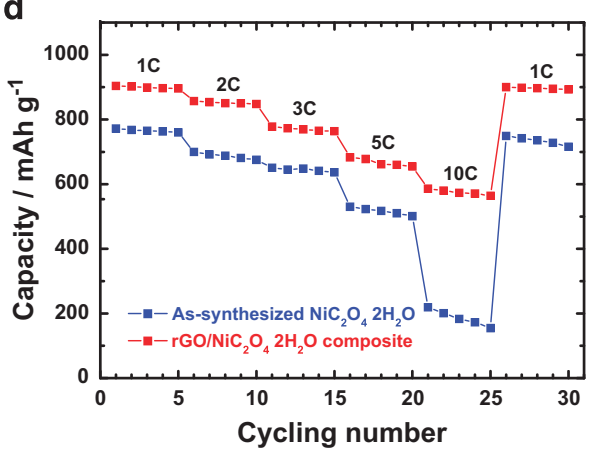

Figure 2 (a) Comparison of the first discharge-charge curves for the $\mathrm{NiC}_{2} \mathrm{O}_{4} \cdot 2 \mathrm{H}_{2} \mathrm{O}$ and $\mathrm{NiC}_{2} \mathrm{O}_{4} \cdot 2 \mathrm{H}_{2} \mathrm{O} / \mathrm{rGO}$ composite electrodes measured by applying a current density of $500 \mathrm{~mA} \mathrm{~g}^{-1}\left(0.5 \mathrm{C}\right.$-rate) at $25^{\circ} \mathrm{C}$; (b) the resulting cyclability over 100 cycles; (c) rate capabilities for the $\mathrm{NiC}_{2} \mathrm{O}_{4} \cdot 2 \mathrm{H}_{2} \mathrm{O}$ and the $\mathrm{NiC}_{2} \mathrm{O}_{4} \cdot 2 \mathrm{H}_{2} \mathrm{O} / \mathrm{rGO}$ composite electrodes measured by applying the same currents for both discharge and charge at $25^{\circ} \mathrm{C}$; and (d) the resulting cyclability and recovery of the capacity at $0.5 \mathrm{C}$-rate after the test at $10 \mathrm{C}$-rates.

agrees with the XRD pattern reported by Lopez et al. ${ }^{24}$ and Kolezynski et $a l .{ }^{40}$ In addition, the dehydration did not alter the original particle morphology of the nanorods (Figures 1c-f), as shown in Supplementary Figures S2b and c.

The presence of carbon is further confirmed via the Raman spectrum (Supplementary Figure S3, top); specifically, two bands appeared at 1347 and $1591 \mathrm{~cm}^{-1}$. The latter is due to the $\mathrm{C}=\mathrm{C}$ symmetrical vibration that results from the formation of the crystalline $\pi$-bond $\mathrm{sp}^{3}$ character. In addition, the coexistence of the rGO and $\mathrm{NiC}_{2} \mathrm{O}_{4} \cdot 2 \mathrm{H}_{2} \mathrm{O}$ spectra provides evidence of the formation of a $\mathrm{NiC}_{2} \mathrm{O}_{4} \cdot 2 \mathrm{H}_{2} \mathrm{O} / \mathrm{rGO}$ composite (Supplementary Figure S2). The content of the carbon was approximately $3 \mathrm{wt} . \%$, as analyzed by a $\mathrm{CHN}$ analyzer, which agrees with the added amount of rGO during the composite synthesis stage. The presence of electro-conducting rGO was effective in improving the electrical conductivity to approximately $7.1 \times 10^{-4} \mathrm{~S} \mathrm{~cm}^{-1}$ for the $\mathrm{NiC}_{2} \mathrm{O}_{4} \cdot 2 \mathrm{H}_{2} \mathrm{O} / \mathrm{rGO}$ composite. The conductivity is slightly lower than that of several carbon-coated electrode materials. ${ }^{41-43}$ Because heating the $\mathrm{NiC}_{2} \mathrm{O}_{4} \cdot 2 \mathrm{H}_{2} \mathrm{O}$ can cause thermal decomposition into metal or metal oxide, carbonization is not available to preserve the original structure and morphology of $\mathrm{NiC}_{2} \mathrm{O}_{4} \cdot 2 \mathrm{H}_{2} \mathrm{O}$. The measured electrical conductivity of the rGO-free $\mathrm{NiC}_{2} \mathrm{O}_{4} \cdot 2 \mathrm{H}_{2} \mathrm{O}$ was approximately $1.3 \times 10^{-7} \mathrm{~S} \mathrm{~cm}^{-1}$. Plate-like particles clearly appeared (Figure 1e), which can be ascribed to the presence of rGO. Furthermore, the $\mathrm{NiC}_{2} \mathrm{O}_{4} \cdot 2 \mathrm{H}_{2} \mathrm{O}$ nanorods are evidently loaded onto the flat rGO plates (Figure 1f). The nitrogen adsorption-desorption isotherm exhibits a type-IV isotherm, with a hysteresis loop between the H1and $\mathrm{H} 2$ types, which is related to the capillary condensation behavior of the produced powders (Supplementary Figures S4a and b). This is further evidenced by the pore size distribution (Supplementary Figures $\mathrm{S} 4 \mathrm{c}$ and d). Note that the pore volume varies greatly for the $\mathrm{NiC}_{2} \mathrm{O}_{4} \cdot 2 \mathrm{H}_{2} \mathrm{O} / \mathrm{rGO}$ composite.
The larger pores provided by the rGO plates are likely to facilitate electrolyte penetration into the electrodes, which would help to improve the electrochemical performance.

Electrochemical performance of the $\mathrm{NiC}_{2} \mathrm{O}_{4} \cdot 2 \mathrm{H}_{2} \mathrm{O} / \mathrm{rGO}$ composite Bare and $\mathrm{NiC}_{2} \mathrm{O}_{4} \cdot 2 \mathrm{H}_{2} \mathrm{O} / \mathrm{rGO}$ electrodes were tested in the voltage range of $0-3 \mathrm{~V}$ vs $\mathrm{Li}^{2} / \mathrm{Li}^{+}$by applying a current density of $500 \mathrm{~mA} \mathrm{~g}^{-1}$ (0.5 C-rate) at $25^{\circ} \mathrm{C}$ (Figures $2 \mathrm{a}$ and $\mathrm{b}$ ). Both electrodes exhibited a similar $\mathrm{Li}^{+}$uptake tendency upon discharge (reduction), obtaining discharge capacities of $1109 \mathrm{mAhg}^{-1}$ for the bare electrode and $1072 \mathrm{mAh} \mathrm{g}^{-1}$ for the $\mathrm{NiC}_{2} \mathrm{O}_{4} \cdot 2 \mathrm{H}_{2} \mathrm{O} / \mathrm{rGO}$ electrode. Overall, although there was a slight difference in the discharge capacities, the resulting voltage profiles were similar to each other. Note that there is an obvious difference in the charge (oxidation) capacities: $805 \mathrm{mAh} \mathrm{g}^{-1}$ $\left(72.6 \%\right.$ efficiency) for the bare electrode and $933 \mathrm{mAh} \mathrm{g}^{-1}$ ( $87.5 \%$ efficiency) for the $\mathrm{NiC}_{2} \mathrm{O}_{4} \cdot 2 \mathrm{H}_{2} \mathrm{O} / \mathrm{rGO}$ electrode. Two recent compounds, $\mathrm{Cu}_{1 / 3} \mathrm{Co}_{2 / 3} \mathrm{C}_{2} \mathrm{O}_{4} \cdot \mathrm{xH}_{2} \mathrm{O} / \mathrm{FGO}^{38}$ and $\mathrm{FeC}_{2} \mathrm{O}_{4} \cdot 2 \mathrm{H}_{2} \mathrm{O}^{40}$, exhibited large irreversible capacities upon the first cycle. This improvement in the reversibility can mainly be ascribed to the enhanced electrical conductivity of the $\mathrm{NiC}_{2} \mathrm{O}_{4} \cdot 2 \mathrm{H}_{2} \mathrm{O} / \mathrm{rGO}$ composite, in which the electro-conducting $\mathrm{rGO}$ had a significant role in improving the conductivity and porosity of the electrode, which allows the electrolyte to more readily penetrate the electrode. These synergistic effects were further confirmed for long-term cyclability (Figure 2b); namely, 54\% for the bare electrode and $85 \%$ for the $\mathrm{NiC}_{2} \mathrm{O}_{4} \cdot 2 \mathrm{H}_{2} \mathrm{O} / \mathrm{rGO}$ electrode. With the help of the $\mathrm{rGO}$ induced by the SA-LBL assembly, the $\mathrm{NiC}_{2} \mathrm{O}_{4} \cdot 2 \mathrm{H}_{2} \mathrm{O} / \mathrm{rGO}$ composite can achieve a remarkable electrode performance during the long-term cycling test, which was superior to those of dehydrated $\mathrm{NiC}_{2} \mathrm{O}_{4}$ and the $\mathrm{NiC}_{2} \mathrm{O}_{4} / \mathrm{rGO}$ composite (Supplementary Figures S5a and b). 
a

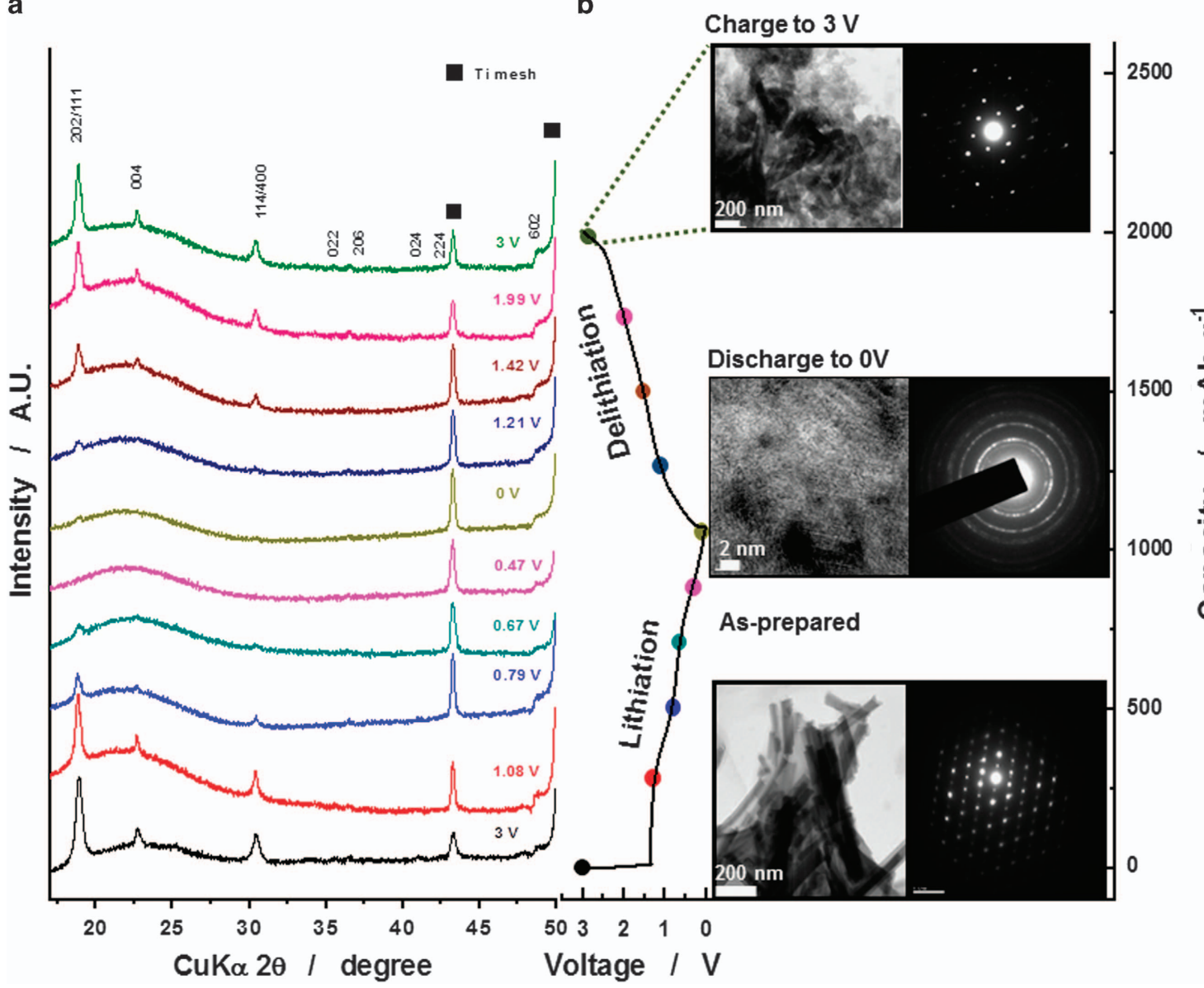

ㅇ
$\frac{1}{2}$
$\frac{1}{0}$
$\frac{0}{0}$
$\frac{0}{0}$

Figure 3 (a) Phase evolution of the $\mathrm{NiC}_{2} \mathrm{O}_{4} \cdot 2 \mathrm{H}_{2} \mathrm{O} / \mathrm{rGO}$ composite electrode upon lithiation (reduction) and delithiation (oxidation); (b) left: the first dischargecharge curve, right bottom: TEM bright-field image of the as-prepared composite and the corresponding SAD pattern, right middle: TEM bright-field image of the $\mathrm{NiC}_{2} \mathrm{O}_{4} \cdot 2 \mathrm{H}_{2} \mathrm{O} / \mathrm{rGO}$ composite lithiated to $\mathrm{O} \mathrm{V}$ and the corresponding $\mathrm{SAD}$ pattern, right top: TEM bright-field image of the $\mathrm{NiC}_{2} \mathrm{O}_{4} \cdot 2 \mathrm{H}_{2} \mathrm{O} / \mathrm{rGO}$ composite delithiated to $3 \mathrm{~V}$ and the corresponding SAD pattern. The applied current was $500 \mathrm{~mA} \mathrm{~g}^{-1}$ ( $0.5 \mathrm{C}$-rate) at $25^{\circ} \mathrm{C}$ for the sample preparation.

The rate test demonstrated the excellent electrode performance of the $\mathrm{NiC}_{2} \mathrm{O}_{4} \cdot 2 \mathrm{H}_{2} \mathrm{O} / \mathrm{rGO}$ composite compared with that of the rGO-free $\mathrm{NiC}_{2} \mathrm{O}_{4} \cdot 2 \mathrm{H}_{2} \mathrm{O}$ composite. All cells were subjected to discharge and charge at the same current densities, up to a $10 \mathrm{C}$-rate $\left(10 \mathrm{~A} \mathrm{~g}^{-1}\right)$, as shown in Figures $2 \mathrm{c}$ and $\mathrm{d}$. The specific discharge and charge capacities of the bare electrode significantly decreased with the increasing current densities, finally reaching approximately $207 \mathrm{mAh} \mathrm{g}^{-1}$ at a $10 \mathrm{C}$-rate for the charge. Meanwhile, the charge capacities of the $\mathrm{NiC}_{2} \mathrm{O}_{4} \cdot 2 \mathrm{H}_{2} \mathrm{O} / \mathrm{rGO}$ electrode were 901, 855, 778, 684 and $586 \mathrm{mAh} \mathrm{g}^{-1}$ at 1, 2, 3, 5 and $10 \mathrm{C}$-rates, respectively (Figure 2c). Furthermore, these capacities were retained over five cycles (Figure 2d). Importantly, the capacity almost recovered its initial capacity, $899 \mathrm{mAh} \mathrm{g}^{-1}$, after the $10 \mathrm{C}$-rate test when later discharged at the $1 \mathrm{C}$-rate. This performance was evidently better than that of dehydrated $\mathrm{NiC}_{2} \mathrm{O}_{4}$ and $\mathrm{NiC}_{2} \mathrm{O}_{4} / \mathrm{rGO}$ composite (Supplementary Figures $\mathrm{S} 5 \mathrm{c}$ and $\mathrm{d}$ ), although the reason is unknown at present. Additionally, $\mathrm{NiC}_{2} \mathrm{O}_{4} \cdot 2 \mathrm{H}_{2} \mathrm{O} / \mathrm{rGO}$ was tested for supercapacitors because of its excellent electrochemical properties at a high current density (Supplementary Figure S6). The maximum specific capacitance can be obtained at a low current density such as $2 \mathrm{Ag}^{-1}$, which was $242.4 \mathrm{Fg}^{-1}$ in $\mathrm{NiC}_{2} \mathrm{O}_{4} \cdot 2 \mathrm{H}_{2} \mathrm{O}$ and $324.8 \mathrm{Fg}^{-1}$ in the $\mathrm{NiC}_{2} \mathrm{O}_{4} \cdot 2 \mathrm{H}_{2} \mathrm{O} /$ rGO composite, and the $\mathrm{NiC}_{2} \mathrm{O}_{4} \cdot 2 \mathrm{H}_{2} \mathrm{O} / \mathrm{rGO}$ composite exhibited evidently better specific capacitance. The $\mathrm{NiC}_{2} \mathrm{O}_{4} \cdot 2 \mathrm{H}_{2} \mathrm{O} / \mathrm{rGO}$ composite could retain a specific capacitance that was better and more reversible than that of $\mathrm{NiC}_{2} \mathrm{O}_{4} \cdot 2 \mathrm{H}_{2} \mathrm{O}$ for 5000 cycles with higher capacitance, namely $82.8 \%$ for $\mathrm{NiC}_{2} \mathrm{O}_{4} \cdot 2 \mathrm{H}_{2} \mathrm{O}$ and $92.8 \%$ for the $\mathrm{NiC}_{2} \mathrm{O}_{4} \cdot 2 \mathrm{H}_{2} \mathrm{O} / \mathrm{rGO}$ composite. We believe that the superior performance of $\mathrm{NiC}_{2} \mathrm{O}_{4} \cdot 2 \mathrm{H}_{2} \mathrm{O} / \mathrm{rGO}$ is due to the presence of $\mathrm{rGO}$, which improves the electron transport through the rGO matrix efficiently towards the $\mathrm{NiC}_{2} \mathrm{O}_{4} \cdot 2 \mathrm{H}_{2} \mathrm{O} / \mathrm{rGO}$ nanorods.

\section{Postcycling $\mathrm{NiC}_{2} \mathrm{O}_{4} \cdot 2 \mathrm{H}_{2} \mathrm{O} / \mathrm{rGO}$ composite}

Because of the high reversibility of the present electrodes, the crystal structure was investigated by ex situ XRD (Figure 3a). A Ti current collector was used as an internal standard to calibrate the XRD patterns. Although the $\mathrm{NiC}_{2} \mathrm{O}_{4} \cdot 2 \mathrm{H}_{2} \mathrm{O} / \mathrm{rGO}$ was lithiated (reduced) to $1.08 \mathrm{~V}$, there was no significant change in the crystal structure. Interestingly, further lithiation to $0.79 \mathrm{~V}$ greatly decreased the relative intensity of the XRD pattern. The intensity was further lowered at $0 \mathrm{~V}$, and no peaks were observed, indicating that the resulting product was transformed into low crystallinity or amorphous products (Figure 3a). These tendencies are well known for the conversion reactions of metal oxides ${ }^{44,45}$ which commonly result in products such as amorphous metals and $\mathrm{Li}_{2} \mathrm{O}$. The TEM images clearly indicate the formation of nanodomains (Figure $3 \mathrm{~b}$ ), and the resulting selected-area diffraction indicates that the domains are composed of $\mathrm{Ni}$ metal $(F m 3 m)$.

The chemical state of Ni was also monitored via XPS and ToF-SIMS (Figure 4). The oxidation state was stabilized at $\mathrm{Ni}^{2+}(835.5 \mathrm{eV})$ for the 


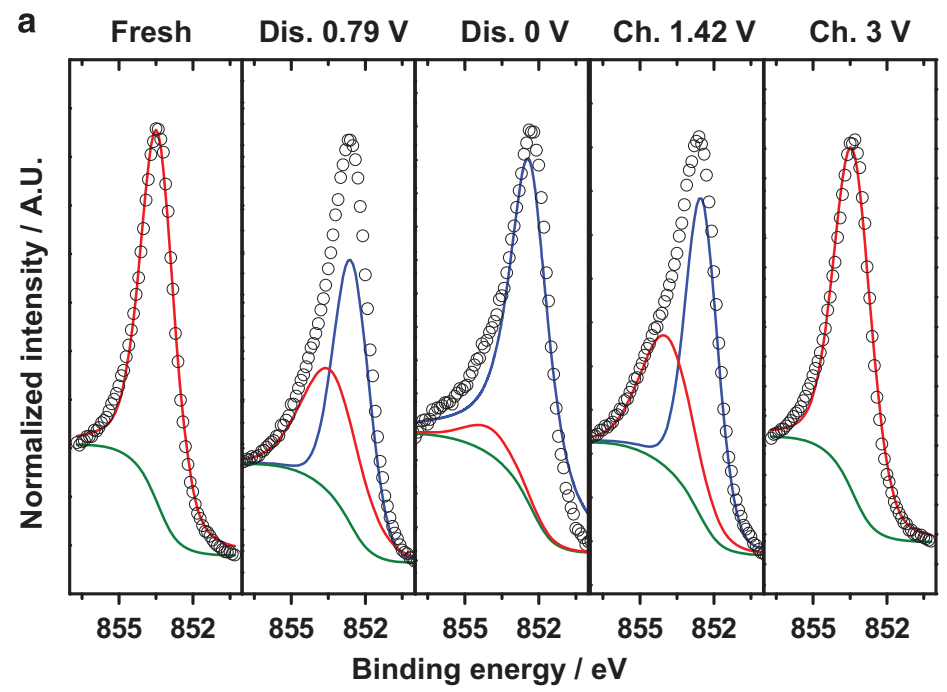

b
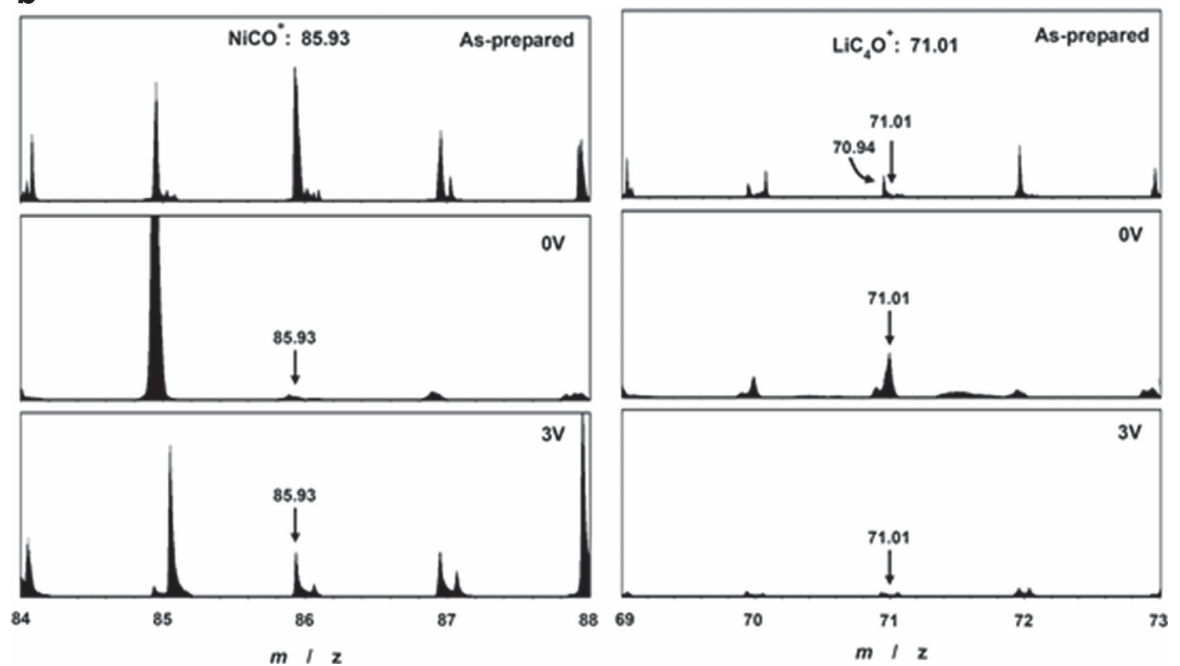

Figure 4 (a) XPS spectra of the $\mathrm{NiC}_{2} \mathrm{O}_{4} \cdot 2 \mathrm{H}_{2} \mathrm{O} / \mathrm{rGO}$ composite electrode upon lithiation (reduction) and delithiation (oxidation); (b) ToF-SIMS spectra of the $\mathrm{NiC}_{2} \mathrm{O}_{4} \cdot 2 \mathrm{H}_{2} \mathrm{O} / \mathrm{rGO}$ composite electrode upon lithiation (reduction) and delithiation (oxidation), left: $\mathrm{NiCO}^{+}$positive fragment $(m=85.93)$ and $\mathrm{right} \mathrm{LiC}_{4} \mathrm{O}^{+}$ positive fragment $(m=71.01)$. The applied current was $500 \mathrm{~mA} \mathrm{~g}^{-1}\left(0.5 \mathrm{C}\right.$-rate) at $25^{\circ} \mathrm{C}$ for the sample preparation.

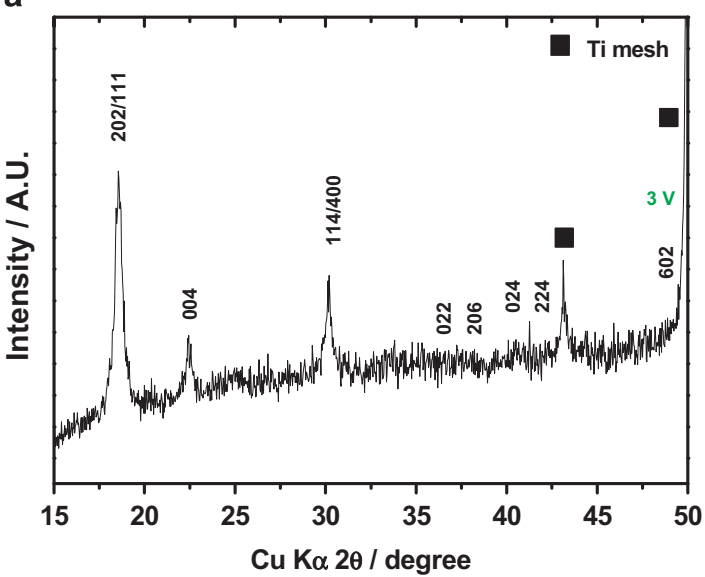

b

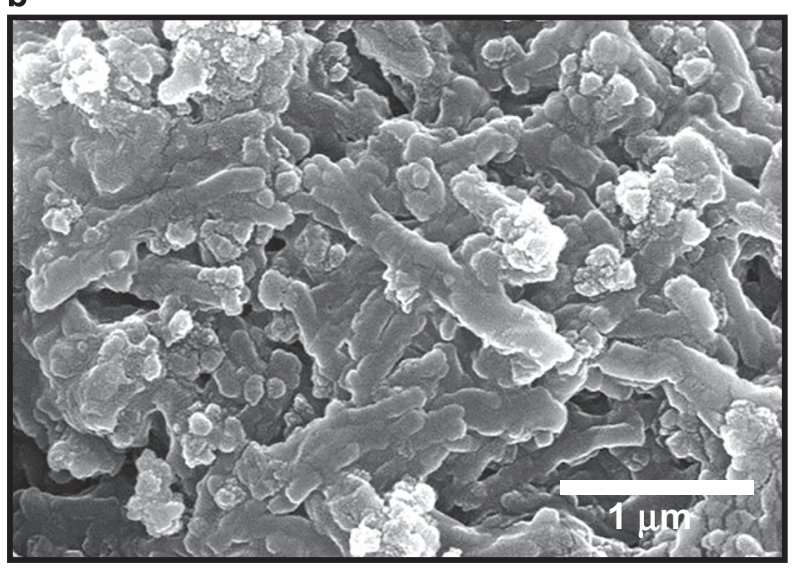

Figure 5 (a) XRD pattern of the $\mathrm{NiC}_{2} \mathrm{O}_{4} \cdot 2 \mathrm{H}_{2} \mathrm{O} / \mathrm{rGO}$ composite electrode after 100 cycles and (b) the resulting SEM image. 
fresh $\mathrm{NiC}_{2} \mathrm{O}_{4} \cdot 2 \mathrm{H}_{2} \mathrm{O} / \mathrm{rGO}$ (Figure $4 \mathrm{a}$ ). Broadening and shifting in the binding energy towards a lower energy were also observed as the electrodes were lithiated at $0 \mathrm{~V}$. The observed binding energy of $852.4 \mathrm{eV}$ was due to the formation of metallic $\mathrm{Ni}$, which can be observed in TEM images (Figure 3b). Surprisingly, the $\mathrm{NiCO}^{+}$ fragment, which was observed in the fresh state, was negligible at $0 \mathrm{~V}$ (Figure $4 \mathrm{~b}$ left), while the $\mathrm{LiC}_{4} \mathrm{O}^{+}$fragment was observed in the ToF-SIMS data (Figure $4 \mathrm{~b}$ right). This explains how the divalent nickel oxalate was transformed into lithium oxalate, leaving traces of metallic $\mathrm{Ni}$, and the resulting crystallinity was amorphous or of low crystallinity. The variation in the binding energies for $\mathrm{C}$ also verified the formation of lithium oxalate (Supplementary Figure S7). Compared with that of the fresh state, the increase in the binding energy at $290 \mathrm{eV}$ indicated the formation of oxalate-related compounds. This reaction is similar to conversion reactions, but the reaction products are metal and lithium oxalate instead of $\mathrm{Li}_{2} \mathrm{O}$, which is more noticeable in the case of conversion reactions for metal oxides. ${ }^{45}$ Using X-ray absorption and Fourier transform infrared studies, Aragon et al. ${ }^{25}$ also observed this similarity in the formation of $\mathrm{Li}_{2} \mathrm{C}_{2} \mathrm{O}_{4}$ when lithiated (reduced).

Upon charging (oxidation), the relative intensity of the XRD pattern gradually increased and was completely recovered to its state before discharge (Figure 3a). The TEM data also exhibited the maintenance of the nanorod morphology and the recovery of crystallinity in the selected-area diffraction pattern (Figure $3 b$ ). The binding energy of $\mathrm{Ni}$ was restored to its original state under delithiation, showing a shift toward a higher binding energy (Figure 4a). At $3 \mathrm{~V}$, the observed binding energy corresponded to $\mathrm{Ni}^{2+}(835.5 \mathrm{eV})$, which was the same state as that of the original electrode. Again, note that the relative intensity of the binding energy at $290 \mathrm{eV}$ was significantly lowered (Supplementary Figure S7). Furthermore, the fragment that appeared as $\mathrm{LiC}_{4} \mathrm{O}^{+}(m=71.01)$ was only barely detected in the ToF-SIMS data (Figure $4 \mathrm{~b}$ right), while $\mathrm{NiCO}^{+}(m=85.93)$ was observed once again (Figure $4 \mathrm{~b}$ left). These results verified the occurrence of conversion reactions via the formation of $\mathrm{Ni}$ metal and lithium oxalate upon discharge. Therefore, this reversibility is likely to affect the high coulombic efficiency (87.5\%) for the first cycle of the $\mathrm{NiC}_{2} \mathrm{O}_{4} \cdot 2 \mathrm{H}_{2} \mathrm{O} /$ rGO electrode. The conversion reaction is highly reversible; thus the initial capacity can be retained throughout the cycling test (Figure 2b), even at high rates (Figures $2 \mathrm{c}$ and $\mathrm{d}$ ).

This reversibility was confirmed in the postcycling electrode (Figure 5). Namely, the resulting XRD pattern clearly exhibited that the original crystal structure after 100 cycles had been maintained (Figure 5a), as its structure was similar to the as-prepared $\mathrm{NiC}_{2} \mathrm{O}_{4} \cdot 2 \mathrm{H}_{2} \mathrm{O} / \mathrm{rGO}$ (Figure 1b), although a slight deviation in the lattice parameters was observed for the cycled $\mathrm{NiC}_{2} \mathrm{O}_{4} \cdot 2 \mathrm{H}_{2} \mathrm{O} / \mathrm{rGO}$ electrode (Supplementary Table S1). In addition, the original morphology, which was stable in the forms of nanorods, was retained, even after extensive cycling (Figure 5b). The only difference between $\mathrm{NiC}_{2} \mathrm{O}_{4} \cdot 2 \mathrm{H}_{2} \mathrm{O}$ and $\mathrm{NiC}_{2} \mathrm{O}_{4} \cdot 2 \mathrm{H}_{2} \mathrm{O} / \mathrm{rGO}$ is the presence of conductive graphene, onto which $\mathrm{NiC}_{2} \mathrm{O}_{4} \cdot 2 \mathrm{H}_{2} \mathrm{O}$ nanorods were applied. The XPS and ToF-SIMS data shown in Figure 4 and Supplementary Figure S7 clearly demonstrate the formation of the $\mathrm{Li}_{2} \mathrm{C}_{2} \mathrm{O}_{4}$-related compound, which is an insulating compound. From this viewpoint, the presence of conducting graphene likely compensated for the electron transfer, which was impeded by the insulating $\mathrm{Li}_{2} \mathrm{C}_{2} \mathrm{O}_{4}$-related compound. For this reason, the $\mathrm{NiC}_{2} \mathrm{O}_{4} \cdot 2 \mathrm{H}_{2} \mathrm{O} / \mathrm{rGO}$ composite electrode was able to retain its high capacity upon cycling. In addition, the recovery of the original crystal structure and the maintenance of the nanorod morphology both supported the stable electrochemical cycling of the $\mathrm{NiC}_{2} \mathrm{O}_{4} \cdot 2 \mathrm{H}_{2} \mathrm{O} / \mathrm{rGO}$ composite, which was not previously possible.

\section{CONCLUSION}

Nanorods consisting of a $\mathrm{NiC}_{2} \mathrm{O}_{4} \cdot 2 \mathrm{H}_{2} \mathrm{O} / \mathrm{rGO}$ composite were successfully synthesized via hydrothermal and subsequent SA-LBL processes, which utilized electrostatic adsorption between the $\mathrm{NiC}_{2} \mathrm{O}_{4} \cdot 2 \mathrm{H}_{2} \mathrm{O}$ nanorods and $\mathrm{rGO}$ sheets. The $\mathrm{NiC}_{2} \mathrm{O}_{4} \cdot 2 \mathrm{H}_{2} \mathrm{O} / \mathrm{rGO}$ composite exhibited good cyclability, high capacity and reasonable rate performance. The high electrical conductivity clearly promoted the reversible lithiation and delithiation processes that are associated with conversion reactions through the transformation into Ni metal accompanying the formation of a lithium oxalate compound, upon discharge and with the recovery of the original $\mathrm{NiC}_{2} \mathrm{O}_{4} \cdot 2 \mathrm{H}_{2} \mathrm{O}$ upon charging. These findings demonstrate that oxalate-based anode materials are also feasible for use in rechargeable lithium-ion batteries.

\section{ACKNOWLEDGEMENTS}

We thank Miwa Watanabe, Iwate University for her assistance in the experimental work. This research was supported by the Basic Science Research Program through the National Research Foundation of Korea (NRF), funded by the Ministry of Education, Science and Technology of Korea

(NRF-2014R1A2A1A11051197) and by the National Research Foundation of Korea funded by the Korean government (MEST) (NRF-2015M3D1A1069713). This work was also supported by the Human Resources Development of the Korean Institute of Energy Technology Evaluation and Planning (KETEP) grant, funded by the Korean government Ministry of Trade, Industry \& Energy (No. 20154030200630).

1 Armand, M. \& Tarascon, J. M. Building better batteries. Nature 451, 652-657 (2008).

2 Xie, D., Yuan, W., Dong, Z., Su, Q., Zhang, J. \& Du, G. Facile synthesis of porous NiO hollow microspheres and its electrochemical lithium-storage performance. Electrochim. Acta 92, 87-92 (2013).

3 Liu, H., Wang, G. X., Liu, J., Qiao, S. Z. \& Ahn, H. Highly ordered mesoporous NiO anode material for lithium ion batteries with an excellent electrochemical performance. J. Mater. Chem. 21, 3046-3052 (2011).

4 Vu, A., Qian, Y. \& Stein, A. Porous electrode materials for lithium-ion batteries - how to prepare them and what makes them special. Adv. Energy Mater. 2, 1056-1085 (2012).

5 Guo, W. X., Xue, X. Y., Wang, S. H., Lin, C. J. \& Wang, Z. L. An integrated power pack of dye-sensitized solar cell and $\mathrm{Li}$ battery based on double-sided $\mathrm{TiO}_{2}$ nanotube arrays. Nano Lett. 12, 2520-2523 (2012).

6 Yuan, C., Hou, L., Feng, Y., Xiong, S. \& Zhang, X. Sacrificial template synthesis of short mesoporous $\mathrm{NiO}$ nanotubes and their application in electrochemical capacitors. Electrochim. Acta 88, 507-512 (2013).

7 Xing, L. L., Cui, C. X., He, B., Nie, Y. X., Deng, P. \& Xue, X. Y. SnO $/ \mathrm{NiO}$ core-shell nanobelts and their high reversible lithium storage capacity arising from synergisticeffect. Mater. Lett. 96, 158-161 (2013).

8 Myung, S.-T., Takashi, N., Komaba, S., Yoon, C. S., Sun, Y.-K., Amine, K. \& Yashiro, H. Nanostructured $\mathrm{TiO}_{2}$ and its application in lithium-ion storage. Adv. Funct. Mater. 21, 3231-3241 (2011).

9 Myung, S.-T., Kikuchi, M., Yoon, C. S., Yahsiro, H., Kim, S. J., Sun, Y.-K. \& Scrosati, B. Black anatase titania enabling ultra high cycling rates for rechargeable lithium batteries. Energy Environ. Sci. 6, 2609-2614 (2013).

$10 \mathrm{Kim}$, K.-T., Sun, Y.-K. \& Myung, S.-T. Carbon-coated anatase titania as a high rate anode for lithium batteries. J. Power Sources 281, 362-369 (2015).

11 Jung, H.-G., Myung, S.-T., Yoon, C. S., Son, S.-B., Oh, K.-H., Amine, K., Scrosati, B. \& Sun, Y.-K. Microscale spherical carbon-coated $\mathrm{Li}_{4} \mathrm{Ti}_{5} \mathrm{O}_{12}$ as ultra high power anode material for lithium batteries. Energy Environ. Sci 4, 1345-1351 (2011).

12 Roy, P. \& Srivastava, S. K. Nanostructured anode materials for lithium ion batteries. J. Mater. Chem. A 3, 2454-2484 (2015).

13 Larcher, D., Beattie, S., Morcrette, M., Edstrom, K., Jumas, J. C. \& Tarascon, J. M. Recent findings and prospects in the field of pure metals as negative electrodes for Li-ion batteries. J. Mater. Chem. 17, 3579-3772 (2007).

$14 \mathrm{Li}$, T., Li, L., Cao, Y. L., Ai, X. P. \& Yang, H. X. Reversible three-electron redox behaviors of $\mathrm{FeF}_{3}$ nanocrystals as high-capacity cathode-active materials for Li-ion batteries. J. Phys. Chem. C 114, 3190-3195 (2010).

15 Li, C. L., Gu, L., Tsukimoto, S., Van Aken, P. A. \& Maier, J. Low-temperature ionic-liquid-based synthesis of nanostructured iron-based fluoride cathodes for lithium batteries. Adv. Mater. 22, 3650-3654 (2010).

16 Taberna, P. L., Mitra, S., Poizot, P., Simon, P. \& Tarascon, J.-M. High rate capabilities $\mathrm{Fe}_{3} \mathrm{O}_{4}$-based $\mathrm{Cu}$ nano-architectured electrodes for lithium-ion battery applications. Nat. Mater. 5, 567-573 (2006). 
17 Debart, A., Dupont, L., Patrice, R. \& Tarascon, J. M. Reactivity of transition metal (Co, $\mathrm{Ni}, \mathrm{Cu}$ ) sulphides versus lithium: the intriguing case of the copper sulphide. Solid State Sci. 8, 640-651 (2006).

$18 \mathrm{Cho}$, J. Porous Si anode materials for lithium rechargeable batteries. J. Mater. Chem. 20, 4009-4014 (2010)

19 Vaughey, J. T., O'hara, J. \& Thackeray, M. M. Intermetallic insertion electrodes with a zinc blende-type structure for Li batteries: a study of $\mathrm{Li}_{x} \operatorname{InSb}(0<x<3)$. Electrochem. Solid State Lett. 3, 13-16 (2000).

20 Cabana, J., Monconduit, L., Larcher, D. \& Palacin, M. R. Beyond intercalation- based Li-ion batteries: the state of the art and challenges of electrode materials reacting through conversion reactions. Adv. Mater. 22, E170-E192 (2010).

21 Chae, B. M., Oh, E. S. \& Lee, Y. K. Conversion mechanisms of cobalt oxide anode for Li-ion battery: in situ X-ray absorption fine structure studies. J. Power Sources $\mathbf{2 7 4}$, 748-754 (2015).

22 Malini, R., Uma, U., Sheela, T., Ganesan, M. \& Renganathan, N. G. Conversion reactions: a new pathway to realise energy in lithium-ion battery-review. Ionics 15, 301-307 (2009).

23 Guo, Y. G., Hu, J. S. \& Wan, L. J. Nanostructured materials for electrochemical energy conversion and storage devices. Adv. Mater. 20, 2878-2887 (2008).

24 Lopez, M. C., Tirade, J. L. \& Vicente, C. P. Structural and comparative electrochemical study of $\mathrm{M}(\mathrm{II})$ oxalates, $\mathrm{M}=\mathrm{Mn}$, $\mathrm{Fe}, \mathrm{Co}, \mathrm{Ni}, \mathrm{Cu}, \mathrm{Zn}$. J. Power Sources 227, 65-71 (2013).

25 Aragon, M. J., Leon, B., Serrano, T., Vicente, C. P. \& Tirado, J. L. Synergistic effects of transition metal substitution in conversion electrodes for lithium-ion batteries. J. Mater. Chem. 21, 10102-10107 (2011).

26 Leon, B., Vicente, C. P. \& Tirado, J. L. New mixed transition metal oxysalts as negative electrode materials for lithium-ion batteries. Solid State lonics 225, 518-521 (2012).

27 Xu, J., He, L., Liu, H., Han, T., Wang, Y., Zhang, C. \& Zhang, Y. Controlled synthesis of porous anhydrous cobalt oxalate nanorods with high reversible capacity and excellent cycling stability. Electrochim. Acta 170, 85-91 (2015).

28 Malecka, B., Malecki, A., Ciesla, E. D., Tortet, L., Llewellyn, P. \& Rouquerol, F. Some aspects of thermal decomposition of $\mathrm{NiC}_{2} \mathrm{O}_{4} \cdot 2 \mathrm{H}_{2} \mathrm{O}$. Thermochim. Acta 466, 57-62 (2007).

29 Zhan, D., Cong, C., Diakite, K., Tao, Y. \& Zhang, K. Kinetics of thermal decomposition of nickel oxalate dihydrate in air. Thermochim. Acta 430, 101-105 (2005).

30 Luo, H., Zou, D., Zhou, L. \& Ying, T. Ionic liquid-assisted synthesis of transition metal oxalates via one-step solid-state reaction. J. Alloy Comp. 481, L12-L14 (2009).

31 Koo, H. Y., Kim, J. H., Hong, S. K., Han, J. M., Ko, Y. N., Kang, Y. C., Kang, S. H. \& Cho, S. B. Characteristics of Fe powders prepared by spray pyrolysis from various types of Fe precursors as a heat pellet material. Met. Mater. Int. 16, 941-946 (2010).

32 Ahmad, T., Ramanujachary, K. V., Lofl, S. E. \& Ganguli, A. K. Nanorods of manganese oxalate: a single source precursor to different manganese oxidenanoparticles ( $\mathrm{MnO}$, $\left.\mathrm{Mn}_{2} \mathrm{O}_{3}, \mathrm{Mn}_{3} \mathrm{O}_{4}\right)$. J. Mater. Chem. 14, 3406-3410 (2004).

33 Li, M. Y., Dong, W. S., Liu, C.L., Liu, Z. T. \& Lin, F. Q. Ionic liquid-assisted synthesis of copper oxalate nanowires and their conversion to copper oxide nanowires. J. Cryst. Growth 310, 4628-4634 (2008).
34 Lakshmi, B. B., Patrissi, C. J. \& Martin, C. R. Sol-gel template synthesis of semiconductor oxide micro- and nanostructures. Chem. Mater. 9, 2544-2550 (1997).

35 Khan, A. S., Devore, T. C. \& Reed, W. F. Growth of the transition metal oxalates in gels. J. Cryst. Growth 35, 337-339 (1976).

36 Wei, X., Zhang, S., Du, Z., Yang, P., Wang, J. \& Ren, Y. Electrochemical performance of high-capacity nanostructured $\mathrm{Li}\left[\mathrm{Li}_{0.2} \mathrm{Mn}_{0.54} \mathrm{Ni}_{0.13} \mathrm{Co}_{0.13}\right] \mathrm{O}_{2}$ cathode material for lithium ion battery by hydrothermal method. Electrochim. Acta 107, 549-554 (2013).

37 Wang, W. W. \& Zhu, Y. J. Microwave-assisted synthesis of cobalt oxalate nanorods and their thermal conversion to $\mathrm{Co}_{3} \mathrm{O}_{4}$ rods. Mater. Res. Bull. 40, 1929-1935 (2005).

38 Fang, F., Kang, W., Yu, F., Zhang, H. \& Shen, Q. High-rate lithium storge capability of cupric-cobaltous oxalate induced by unavoidable crystal water and functionalized graphene oxide. J. Power Sources 282, 109-117 (2015).

39 Ang, W. A., Gupta, N., Prasanth, R. \& Madhavi, S. High-performance mesoporous iron oxalate anodes for lithium-ion batteries. ACS Appl. Mater. Interfaces 4, 7011-7019 (2012).

40 Kolezynski, A., Handke, B. \& Drozdz-Ciesla, E. Crystal structure, electronic structure, and bonding properties of anhydrous nickel oxalate. J. Therm. Anal. Calorim. 113, 319-328 (2013).

41 Liu, B., Yang, H., Zhao, H., An, L., Zhang, L., Shi, R., Wang, L., Bao, L. \& Chen, T. Synthesis and enhanced gas-sensing properties of ultralong $\mathrm{NiO}$ nanowires assembled with NiO nanocrystals. Sensors Actuat. B Chem. 156, 251-262 (2011).

42 Park, M., Zhang, X., Chung, M., Less, G. B. \& Sastry, A. M. A review of conduction phenomena in Li-ion batteries. J. Power Sources 195, 7904-7929 (2010).

$43 \mathrm{Liu}, \mathrm{X}$. \& Yu, L. Influence of nanosized $\mathrm{Ni}(\mathrm{OH}) 2$ addition on the electrochemical performance of nickel hydroxide electrode. J. Power Sources 128, 326-330 (2004).

44 Han, X., Zhang, F., Xiang, J., Chang, C. \& Sun, J. Preparation and electrochemical performance of micro-nanostructured nickel. Electrochim. Acta 54, 6161-6165 (2009).

45 Arico, A. S., Bruce, P., Scrosati, B., Tarascon, J. M. \& Schalkwijk, W. V. Supported metal oxide and other catalysts for ethane conversion: a review. Nat. Mater. 4, 366-277 (2005).

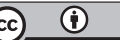

This work is licensed under a Creative Commons Attribution 4.0 International License. The images or other third party material in this article are included in the article's Creative Commons license, unless indicated otherwise in the credit line; if the material is not included under the Creative Commons license, users will need to obtain permission from the license holder to reproduce the material. To view a copy of this license, visit http:// creativecommons.org/licenses/by/4.0/

Supplementary Information accompanies the paper on the NPG Asia Materials website (http://www.nature.com/am) 